http://dx.doi.org/10.5007/1984-784X.2012v12n18p61

\title{
O JORNAL DA SENHORA DE NORONHA ${ }^{1}$
}

\author{
Raúl Antelo \\ Universidade Federal de Santa Catarina
}

Rio de Janeiro, a mediados del siglo XIX: la Rua do Ouvidor

\begin{abstract}
Torrentes de luz envolvian el mar y las montañas que cincundan la bahia rizada por una brisa lijera. Una de ellas tiene la forma de un gigante acostado; y la cara de ese coloso no es otra que la de Luis XVI, cuya nariz borbónica es modelada por la prominencia de una roca. La ciudad nos parecia un anfiteatro caprichoso que comparábamos á esos "Nacimientos" que habiamos visitado en nuestra niñez. Las ondas semejaban de un color en que se confundian el verde, la plata y el oro. Las líneas, claras unas, y vaporosas otras, de una vegetacion tropical suavizaban el esplendor de un cuadro casi indefinible, pero que solo puede sentirse íntimamente á los veinte años.

Fondeado el bergantin, hizo agradable paréntesis á nuestra admiracion la llegada de rápidos esquifes dirigidos por negros que traian á bordo las primicias de aquella tierra hospitalaria. Eran enormes montones de plátanos y de naranjas que los marinos y los pasageros devoran. ${ }^{2}$
\end{abstract}

Con estos elementos, nada exentos de exotismo por cierto, José Tomás, hermano del poeta Carlos e hijo del general Guido, narra la llegada familiar a Rio de Janeiro en 1841. De hecho, la capital del Imperio era una ciudad ajetreada que crecía a simple vista. Tenía en ese momento 270.000 habitantes, de los cuales 110.000 esclavos, pero había, asimismo, un substancial contingente de extranjeros (impedidos de ingresar antes de la transferencia de la corte en 1806). Tres mil ochocientos franceses, 1400 ingleses, 3200 alemanes, 200 holandeses, 400 norteamericanos, otros tantos españoles, 1800 prusianos y un número indefinido de suizos, italianos, austríacos y dinamarqueses, además de 25.000 portugueses. Todos ellos dotaban a la ciudad no sólo de colorido multicultural sino de instituciones innovadoras. Uno de sus visitantes, el inglés Gardner, observó que

Uma das mais belas ruas da cidade é a Rua do Ouvidor, não porque seja mais larga, mais limpa ou melhor pavimentada que as outras, mas porque é ocupada principalmente por modistas francesas, joalheiros, alfaiates, livreiros, sapateiros, confeiteiros, barbeiros. Todas as casas são guarnecidas com uma elegância que um estrangeiro não espera encontrar, e muitas têm janelas

\footnotetext{
1 Este texto, redigido, há muitos anos, a pedido de Paul Verdevoye, para figurar na edição bilíngue do romance de Joana Manso, que deveria ter saído na coleção Archives da UNESCO, dirigida por Amos Segala, como exemplo paradigmático de dupla escrita, português/espanhol, vem hoje a público em espanhol, porque foi a língua escolhida nessa primeira e hipotética edição que nunca chegou a se concretizar e que, ao menos, teve o mérito de autofantasmagorizar o próprio autor do ensaio.

${ }^{2}$ Guido, José Tomás. Escritos. 2. ed. Buenos Aires, Casavalle, 1885, p. 140-1.
} 
formadas de grandes painéis de vidro, semelhantes aos que são agora tão comuns nas grandes cidades da Grã-Bretanha. É a Regent Street do Rio e aí se encontram quase todos os objetos de luxo europeus.

Es, en efecto, el momento en que surgen el Jardín Botánico, la Imprenta Real, la Escuela Médico-Quirúrgica, la Academia Real de Dibujo, Pintura, Escultura y Arquitectura, la Biblioteca Real, fruto de la transferencia de las colecciones de los Braganza, la Academia de Marina y el Teatro São João. Ese nuevo e inquieto contingente urbano se agolpa y circula por unas pocas calles céntricas, en especial, la del Ouvidor, a la que uno de los narradores más destacados del período, Joaquim Manuel de Macedo, le dedicó un tableau, las Memórias da Rua do Owvidor, divulgado por el Jornal do Commercio en 1878 y que se abría admitiendo justamente que:

\begin{abstract}
A Rua do Ouvidor, a mais passeada e concorrida, a mais leviana, indiscreta, bisbilhoteira, esbanjadora, fútil, noveleira, poliglota e enciclopédica de todas as ruas da cidade do Rio de Janeiro, fala, ocupa-se de tudo; até hoje, porém, ainda não referiu a quem quer que fosse a sua própria história.

Se tão elegante, vaidosa, tafulona e rica no século atual, porventura lhe apraz esquecer o passado, para não confessar a humildade de seu berço, pois que é do Ouvidor, cerre bem os ouvidos, porque tomei a peito escrever-lhe a história, mas com tanta verdade e retidão que se lembrando-lhe seus tempos primitivos, ela tiver de amuar-se pelo ressentimento de sua soberba de fidalga nova, há de sorrir depois a algumas saudosas e gratas recordações que avivarei em seu espírito perdidamente absorvido pela garridice e pelo governo da moda. ${ }^{3}$
\end{abstract}

Más allá de la calle peatonal, es en los teatros donde la población local entra en contacto con modas y hábitos europeos. El São Pedro de Alcântara, el de São Januário, el São Francisco, el Santa Leopoldina, el Santa Carolina, el del Comercio o el Liceu Francês, construídos ex profeso o adaptados a partir de antiguos edificios, dan cuenta cabal del movimiento artístico de la corte. El mismo Macedo, nacido en el interior fluminense, en Itaboraí, al retratar su ciudad natal, describe las calles de la infancia y en especial la que

\footnotetext{
3 Macedo, Joaquim Manuel de. Memórias da Rua do Ouvidor. Rio de Janeiro, Tip. Perseverança, 1878. Para Charles de Ribeyrolles, en cambio, "a cidade, há pouco emancipada e ainda em formação, não se tem, por enquanto, adornado das flôres da arte. Mas, porventura, suas ruas não são museus viventes? Há no mundo galeria mais rica, mais bizarra, do que essa mistura de raças que traficam nos portos, nos mercados, nas praças públicas? E se o pensador, sempre inquieto de almas, se o pintor, seu irmão na luz, buscam estudo, nada terão a recolher nessas fisionomias, nessas multidões?”. Apud Bandeira, Manuel y Andrade, Carlos Drummond de. Rio de Janeiro em prosa e verso. Rio de Janeiro, José Olympio, 1965, p. 274.
} 
chamava-se outrora do Senhor do Bom Fim, e chama-se agora do Teatro; porque este edifício, tendo a sua frente para a praça, oferece uma de suas faces laterais à rua que desce até terminar junto da capela do Senhor do Bom Fim, e cortando em dois ângulos retos outra pequena rua que não mencionei por constar de cinco ou seis casas apenas, e que toma o nome do Senhor do Bom Fim. Defronte da porta lateral da capela há uma casa com um limitadíssimo pátio que eu não posso deixar de lembrar. Essa casa foi há perto de quarenta anos um pequeno teatro, e aí encetou a sua gloriosa carreira artística o primeiro ator dramático brasileiro, o célebre e inspirado fluminense João Caetano dos Santos. ${ }^{4}$

Es el mismo João Caetano y son esos teatros los que, tras el correr de los años, no han abandonado la memoria del testigo porteño. José Tomás Guido así los evoca:

\begin{abstract}
Los cuatro teatros que alternativamente frecuentaba contaban con una concurrencia que especialmente para los espectáculos líricos, estaba dotada de la mas rara y viva sensibilidad. Dominaba la escena nacional con su gallardia y con la flexibilidad de sus talentos Juan Cayetano de los Santos que despertaba á veces entre sus compatriotas verdadero delirio. Pocos predilectos de Thalía han sido objeto de mayor admiracion del auditorio, desde que Roscio declamando la comedia antigua, conmovia á los Cónsules, á la plebe, y á las matronas romanas. ${ }^{5}$
\end{abstract}

Es justamente la compañía de João Caetano la que estrena, en el teatro São Januário, en septiembre de 1851, la comedia A família Morel que aquí nos interesa en particular ya que el texto, adaptado de Los misterios de París de Eugène Sue, era firmado por Juana Manso, en realidad, Joana Paula Manso de Noronha, esposa del maestro Sá Noronha, autor de la música incidental de la pieza. Como se puede ver en la prensa de la época, Los misterios de París eran ya, a esa altura, un éxito comercial en Río de Janeiro. Salen en efecto traducidos al portugués por Joaquim José de Rocha entre septiembre y diciembre de 1844 en el Jornal do Comercio pero ya hacía por lo menos un año que circulaban en versión original. "Quem tiver a obra Mystères de Paris, por Eugène Sue, e quiser vendê-la, dirija-se à rua do Ouvidor 87, loja de Mongie", rezaba un aviso de la época. La obra seguía apareciendo cotidianamente en Francia pero, a comienzos del 44, informa Marlyse Meyer, ya debía estar circulando en Río de Janeiro, vendida a 10\$ “à la librarie Belge-Française, rue des Ourives”. Es esa erudita investigadora la que señala, no sin espanto, que apenas iniciada la publicación de la versión brasileña del folletín, en octubre del 44,

\footnotetext{
4 Macedo, Joaquim Manuel de. O Rio do Quarto. Rio de Janeiro, 1869.

${ }^{5}$ Guido, José Tomás. Op. cit., p. 157.
} 
sai, pela primeira vez na história do jornal, um reclame enorme, com tipos garrafais, ocupando toda a sua largura, em rodapé: "ACHAM-se à venda em casa de J. Villeneuve \& Cia., rua do Ouvidor, 65, OS MISTÉRIOS DE PARIS. Primeira Parte - um volume - nítida edição - $1 \$ 00$ ”. O mesmo anúncio se repete em 14 de outubro e, no dia 17, lemos: "Tendo-se esgotado, há dez ou doze dias, a primeira edição dos Mistérios de Paris, e tendo sido muito procurada ultimamente esta obra, participa-se ao público que se está imprimindo a segunda edição, que ficará pronta na semana que vem. SAIRÃO à luz em casa de J. Villeneuve \& Cia., rua do Ouvidor, 65”.

E no número 312, de 3 de novembro de 1844: "Saiu à luz nesta tipografia a segunda edição do PRIMEIRO VOLUME DOS MISTÉRIOS DE PARIS”.

Enquanto é lançada menos de um mês depois uma segunda edição da primeira parte, prossegue a publicação em volume das outras partes, ao mesmo tempo que, mais adiantada, continua a série no jornal. Em 26 de novembro, repete-se o anúncio anterior e mais: o quarto volume. E assim por diante até o FIM, vindo depois o oitavo, o nono e o décimo volume, em 12 de fevereiro de 1845. Enquanto isso, Laemmert e outros livreiros franceses anunciam: "OS MISTÉRIOS DE PARIS - 160 gravuras chegadas de Paris com cenas mais salientes, mais interessantes, a vista dos lugares, gravuras destinadas para acompanhar a edição brasileira em dez volumes; estão impressas no mesmo formato e podem ser encadernadas juntamente.”6

En otras palabras, A familia Morel no hace sino aprovechar la boga del folletín de Sue, aliando literatura y mercado. No es, ciertamente, el hecho de su autora ser una mujer lo que podía merecer reprobación en el medio cultural carioca. Bueno es recordar que una de las primeras novelas brasileñas, Aventuras de Diófanes, no menos inspirada por motivo europeo (es una imitación de Fénelon) pertenece a Tereza Margarida da Silva e Orta ${ }^{7}$ Quizás sea

\footnotetext{
${ }^{6}$ Meyer, Marlyse. Folhetim. Uma história. São Paulo, Companhia das Letras, 1996, p. 283-4. Otro viajero, el ya citado Charles de Ribeyrolles, también señala en 1859 que “o verdadeiro entretenimento público no Rio é o teatro. Tôdas as classes o apreciam, freqüentam-no, têm nêle a sua localidade, apesar do calor. O de São Pedro de Alcântara, no Largo do Rossio, é digno das maiores cidades; as cenas secundárias do São Januário e o Ginásio valem certamente, como artistas e como repertório, as pequenas platéias de Londres. Mas, o mais procurado, o mais rico e melhor instalado é o grande teatro lírico italiano. A direção, largamente subvencionada, faz concorrência, para os contratos, às academias de música mais afamadas da Europa; e se nem sempre apresenta vozes frescas, os prodígios, acontece-lhe às vêzes contar em seu elenco franco-italiano celebridades e talentos os mais raros." Op. cit., p. 274.

${ }^{7}$ Hermana del moralista Matias Aires, autor de Reflexões sobre a vaidade dos homens, la paulista Tereza Margarida da Silva e Orta publica en 1752 las Maximas de Virtude e Formosura, com que Diófanes, Climenéia e Hemirena, Principes de Tebas, venceram os mais apertados lances da desgraça con el anagrama Dorothea Engrassia Tavareda Dalmira. La edición de 1777 aparece como Aventuras de Diófanes imitando o sapientíssimo Fenelon na sua Viagem de Telemaco y la de 1818, con título nuevamente alterado, História de Diófanes, Climenéia e Hemirena, Príncipes de Tebas. A ella debe sumerse en el siglo XVII la poetisa Rita Joana de Souza y en el XVIII, Angela do Amaral Rangel. Brito Broca agrega: "Somente cem anos depois, apareceria o primeiro periódico literário feminino no Brasil. Intitulava-se o Jornal das Senhoras e tratava, além de literatura e arte, de modas e mundanidades, representando, assim mesmo, uma grande conquista para a época. Teve a audácia de levar avante essa iniciativa a escritora baiana Violante de Bivar. No artigo de apresentação, Joana Paula Manso de Noronha dizia a certa altura "haver gente que considera o progresso do gênero humano uma heresia e os literatos como uma casta de vadios". "Ora, uma senhora à testa da redação de um jornal! que bicho de sete cabeças!" O periódico lutou com grandes dificuldades, como é fácil calcular, não faltando quem hostilizasse o empreendimento dessas femmes savantes. A folha durou, apesar disso, quatro anos, embora Violante de Bivar lhe tivesse abandonado a direção dentro de algum tempo para ir fundar outro periódico do mesmo gênero, $O$ Domingo, que viveu cerca
} 
más seguro ubicar los recaudos en la separación entre la incipiente cultura popular y la alta literatura de extracción europea, esta sí, identificada con la función estatal y ajena por completo al ámbito doméstico femenino. Uno de los alegatos más contundentes en ese sentido lo firma José Mármol, allí mismo, en Rio de Janeiro. Por ser poco o nada conocido lo transcribo integralmente ya que nos ayuda a entender la posición de la señora de Noronha.

\section{Poesia e matrimonio}

Ha huma cousa eterna como a natureza de Deos, de quem emana, - que vive hoje como viveo no dia em que com hum sopro de seus divinos labios, fez Deos esta machina que se chama Universo, com a mesma facilidade com que hum fabricante de vidros faz huma garrafa; - huma cousa que viveo na Grecia e no Oriente, no cume do Sinay e nos desertos do Egypto, nos rochedos do Atlas e nas margens do Tibre; e finalmente em todo o mundo, desde os tempos remotissimos em que Jacob se casou com as duas irmãs Rachel e Lia, até à epocha ainda proxima em que a rainha Carolina fazia de hum correio hum camarista, e os reis D. João VI e Carlos IV faziam da fidelidade conjugal o problema de suas meditações. - Huma cousa, que só muda de forma no decurso de hum anno, de hum mez e de hum dia, como as mulheres de trajos ou de amores, porém logica e immutavel em seu espirito, como os velhos em sua obstinação.

Esta cousa he a poesia. Palavra adaptavel a todas as definições, como a virtude, - que cada hum tem direito de entendel-a a seu modo, como a liberdade d"imprensa, e que eu me absterei de definir, como de fallar de liberdade em Buenos-Ayres, ou de eleições em Pernambuco.

Ha outra cousa igualmente eterna, porque he mai da desgraça humana, que nasceo no paraiso, ao pé da arvore da sciencia, e acabará com a trombeta final; e esta cousa he o instincto que aproxima o homem á mulher, (ou a mulher ao homem, como quizerem); instincto semi-divino, semi-infernal, que começou por ser prodigo, e acabou no extremo das Religiões e do Christianismo por ser unico, e legalisado com o nome de matrimonio. Porém não fallamos do matrimonio Brahmanico, nem do matrimonio do Alcorão; - Deos nos livre d"isso! - fallamos do matrimonio Catholico, o melhor que conhecemos, porque somos Catholicos, e não podemos dizer outra cousa. Este matrimonio reduz-se, como todos sabem, e alguem a seu pesar, a união indissoluvel de hum só homem com huma só mulher; salvo as excepções que traz comsigo toda a regra geral, por muito boa e santa que ella seja.

Mas, ha tambem duas cousas heterogeneas na ordem moral, como a agua e o fogo na ordem physica, como a assembléa representativa e o ministerio responsavel na ordem social, e como a pobreza e a felicidade na ordem domestica. Estas duas cousas são a poesia e o matrimonio.

Dois homens quizeram poetisar a mulher casada, e precisaram recorrer ao inferno e ao céo, para procurar, este a sua Beatriz, aquelle a sua Eva; e mesmo assim, Deos sabe se Milton e Dante não ficaram mais descontentes de suas obras, que Luiz Philippe da conquista de Tahiti. Depois d"elles ninguem ha ousado cantar o matrimonio. O poeta comico faz descer o panno com o casamento que termina a sua comedia; primeiro, porque a benção nupcial he o officio de defuntos da poesia; segundo, porque todos sabem o que o poeta calla.

de um ano, desaparecendo com a morte da diretora". Cf. "As mulheres na literatura brasileira" (1953) in Românticos, pré-românticos, ultra-românticos. Vida literaria e Romantismo brasileiro. Pref. Alexandre Eulálio, São Paulo, Polis/INL/MEC, 1979, p. 77. 
Não ha comedia que principie por hum casamento, e ha muitas que começam por hum enterro; o que prova que hum enterro he menos prosaico que hum matrimonio.

O poeta dramatico costuma fazer representar o casamento desde a primeira scena; porém sempre com hum terceiro, que acaba por transtornar o matrimonio, dando huma punhalada na sua Adele, ou envenenando a sua Elvira. Por que só ha hum caso em que o casamento he poetico, e he quando o marido he hum tyranno, que não comprehende sua mulher, e esta não tem mais de vinte cinco annos; pois se passa d"essa idade, a sua desgraça pertence ao confissionario e não ao poeta. Oh! he huma verdadeira desgraça, digna da lyra de Virgilio ou do cinzel de Miguel Angelo, quando huma senhora se empenha em que seu marido não a comprehenda! Porém, para qual dos dous he a desgraça? Eu o ignoro. Virgilio, ou Miguel Angelo, escolheriam para a sua descripção, ou para a sua estatua, a figura de ambos que mais lhe conviesse.

Toda a poesia da vida se acha personificada n"esse céo inconstante que se chama mulher: n"esse bello defeito da natureza, como lhe chama Milton; porém he necessario vel-a pelo prisma da imaginação, em toda a pureza, em toda a virgindade da innocencia; alimentando a vaidade do homem a esperança de respirar algum dia o halito de ambar d"essa flor ainda em botão.

Então, seus olhos são dous astros da via-lactea; - seu seio, he como a onda graciosa de hum mar de leite, e causa vertigens a quem o vê, como o vinho de Xerez a quem o bebe. Seus braços, como dois raios matutinos, fazem sonhar com o seu primeiro abraço; - e sua alma! oh! a alma de huma mulher solteira e virgem he a metade de sua poesia, como hum marido zeloso a metade de sua desgraça!

Mas, casa-se esta mulher, e começa a prosa, bem como a prole; adeos braços, adeos olhos, adeos tudo; sahe a poesia pela mesma porta, por onde entrou o marido!

Nos sonetos de Petrarca, e nas canções de Tasso, não encontrariamos os nomes de Laura e de Leonor, se estas tivessem sido alguma cousa mais que suas amantes.

$\mathrm{E}$ tudo isto tem, como todas as cousas, a sua rasão. O amor sem os seus inconvenientes e sem o seu mysterio, he como o Sandwich sem vinho de Bordeaux, - não serve.

Desde que nada temos a desejar na mulher, nada temos a admirar. Desde que nada admiramos, nada poetisamos; isto he huma verdade.

Póde a poesia corresponder-se com a mulher alheia, como se corresponde o poeta; isto tambem he verdade. Com a propria mulher, porém, he impossivel, e se he possivel para o poeta marido, não o he para o publico, que d"elle zombaria quando enthusiasmado quizesse cantar as graças de sua mulher.

A amada do poeta desperta a inspiração pela sua belleza, e a melancolia pelos inconvenientes da posse. A melancolia do poeta, com as imagens vivas e palpitantes de sua paixão, interessam logo ao publico, e principalmente as mulheres, que invejam a felicidade de ser cantadas. Porém, de que póde queixar-se hum marido? ai d"elle se chegar a fazel-o!

Mas quando dizemos que a poesia e o matrimonio não andam jamais unidos, livre-nos Deos de quere dizer com isso que aquella he o patrimonio de todas as mulheres solteiras. Isto tambem tem suas excepções, como a constancia de todas ellas.

Byron dizia (e Byron entendia da materia), que depois dos desenove já não contava os annos de huma mulher. Nós, porém, pensamos com Balzac, que os annos de huma mulher devem contar-se dos desoito aos trinta, - nem mais nem menos. No circulo d"esses doze annos acham-se encerrados toda a poesia e todo o amor de huma mulher, porque a sua intelligencia acha-se desenvolvida a par do seu coração, e a energia do corpo e do espirito em seus 90 graos. Huma mulher d"estas quando existe na alma hum pouco de melancolia, e hum vaso de ponche quando ha frio, são os dous confortables da vida humana. N"essa idade, os sacrificios e a abnegação são irmãos gemeos do amor. Antes dos desoito annos, não ha na alma da mulher nem bastante força de paixão, nem bastante arte; e a arte he para o amor o que he a luz para huma pintura de Raphael.

Depois dos trinta annos, começa a vida da mulher a abandonar o peito, e a tomar posse do estomago e da cabeça. Ama-se menos e calcula-se mais. Cuida-se mais no rosto, do que no amor. Huma d"estas mulheres não concorreria a huma entrevista em dia humido com receio de constipar-se. Perdoai, amaveis excepções; eu sou homem que nunca fallo nem receio, sem excepções, e com generosidade! Porém voltemos á poesia e ao matrimonio, e digamos por 
ultimo (porque tudo deve ter seu termo, cousa que melhor que nós deveriam saber os que governam); que se a poesia he filha do céo, como disse Homero, o matrimonio não he seu irmão; sem querer por isto que seja filho do inferno, como parece pretendel-o George Sand. Será filho de algum outro; conhecemos grande numero de bons filhos de máos pais.

O matrimonio he bom, qualquer que seja seu pai; he christão, social, eminentemente moral, porém não poetico; - isto he tudo quanto dizemos.

Somos extravagantes em tudo, como em nosso modo de escrever; - algumas vezes pensamos em casar-nos, porém a idéa de repudiar nossa primeira esposa, a poesia, por huma nova consorte, desterrou de nós esse pensamento. Porque, ainda, quando não cante as graças de sua mulher achamos alguma cousa de prosaico em hum poeta-marido, dote que lhe traz comsigo a senhora.

Nós, que não escrevemos para que nos acreditem, mas sim para que nos ouçam, desconfiamos de nossa reputação, quando ao voltar algum dia á nossa patria, entregarmos a hum impressor, por hum punhado de metal, o fructo de nossos trabalhos, nos longos annos de nosso desterro; e o escalpelo do critico fizer a analyse anatomica de nossas crenças, apresentadas já com o sorriso de Figaro, já com o sarcasmo de Byron, ou com a gravidade de Descartes; porém se no fundo de nossas paginas acharem huma só verdade, desejamos que se contentem com ella, como nós nos contentamos, quando achamos huma só virtude no coração de hum homem. Porém, se severos em sua critica, puzerem em duvida nossa moral, então dir-lhe-hemos: "não temos mais; dai-nos alguma da vossa". ${ }^{8}$

José Mármol

\section{El Jornal das Senhoras}

Aunque el maestro Noronha rinda a su esposa "Tributo de afetuosa estima" (Jornal das Senhoras, 21 junio 1852, p. 199) ensalzándola con ditirambos de aficionado,

Joana Paula Manso de Noronha

O mais nobre coração teu peito encerra

Amizade, virtude, amor, constância

Não posso resistir aos teus agrados

Ninguém mais do que cultos te rende,

a pesar de ello, no debía ser cómoda la situación de su esposa en la Corte fluminense. Juan Bautista Alberdi, en una de sus visitas, observa que "la mujer de Río es negra, pequeña, flaca, mal configurada, sin gracia. No tiene sino los bellos ojos de la mujer intertropical. La mujer de Tucumán reúne a este mérito, el del color blanco y la gracia andaluza. (...) En la 
sociedad las mujeres se paran a la entrada de una visita, aunque sea de hombre. Visten mal y su trato es mezquino y de una gravedad de mal gusto. Está lejos de poseer la dignidad de la mujer europea ni la del Plata. En todo se advierte que la mujer es un ente abyecto y degradado aquí"9 lo que, en parte, justifica que el activismo feminista, cuando no abolicionista y republicano, fuese incluso más intenso que en Buenos Aires o Montevideo, como lo prueban Narcisa Amalia o Beatriz Francisca de Assis Brandão, socia honoraria, esta última, del Instituto Histórico e Geográfico, a instancias de Joaquim Norberto. Por otro lado, tenemos la prédica de la prensa femenina (O Jornal das Senhoras, Bello Sexo, $A$ mulher, A Família, O Domingo y, hacia fines del siglo, O Quinze de Novembro do Sexo Feminino) cuyo soporte teórico era, entre otras obras, la Vindication of Rights of Woman de Mary Wollstonecraft, traducida por Nísia Floresta Brasileira Augusta (es decir, Dionísia Gonçalves Freire Pinto) escritora de Floresta, Rio Grande del Norte (1810-1885), que lo vierte con el título de Direitos das Mulheres e Injustiça dos Homens (Recife, 1832). Las ideas de Mary Wollstonecraft, famosa como líder feminista y no menos como madre de Mary Shelley, obtienen la inmediata adhesión de Joana M. de Noronha y otras autoras de la época. Leemos, por ejemplo, en O Jornal das Senhoras, que la emancipación moral de la mujer "é o conhecimento verdadeiro da missão da mulher na sociedade; é o justo gozo dos seus direitos, que o brutal egoísmo do homem lhe rouba, e dos quais a deserda, porque tem em si a força material, e porque ainda se não convenceu que um anjo lhe será mais útil que uma boneca"10. En la divulgación de ese ideario, otra argentina residente en Río de Janeiro, Maria Benedita de Oliveira Barbosa (?-1886), se presenta con el seudónimo de Zaira (anagrama, por lo demás, de Aires, los buenos y originales) en un libelo: Zaira Americana mostra as vantagens que a sociedade inteira obtém da ilustração, virtudes e perfeita educação da mulher como mãe e esposa do homem (Rio de Janeiro, Typographia Dous de Dezembro, 1853).

Por lo tanto, cuando el año nuevo de 1852, Joana Manso de Noronha publica en la Typografia Parisiense de la rua do Ouvidor ese primer número de su periódico de modas,

\footnotetext{
${ }^{8}$ Mármol, José. "Poesia e matrimonio. Fragmentos de minha carteira de viagem". Ostensor Brasileiro. Rio de Janeiro, 1845, p. 210-2.

9 Alberdi, Juan Bautista. Memorias e impresiones de viaje. Ed. por Joaquín V. Gonzalez. Buenos Aires, La Facultad, 1924, p. 273-4.

10 Noronha, Joana P. Manso de. "Emancipação moral da mulher". Jornal das Senhoras. Rio de Janeiro, 25 ene. 1852, p. 12-13.
} 
http://dx.doi.org/10.5007/1984-784X.2012v12n18p61

literatura, bellas artes, teatro y crítica, el Jornal das Senhoras, no estamos ante un hecho aislado sino ante una experiencia concreta de emancipación moral de la mujer en un espacio urbano ya configurado. Ello no obsta que esa emancipación sea aún tímida e inestable, mezclada a menudo con reivindicaciones políticas, económicas, de ascenso social o prestigio mundano y comúnmente indiferenciada en relación a su objeto, del que es incapaz de distanciarse crítica o irónicamente. Ese carácter ambiguo del imperativo ético (ser ciudadana pero también ama de casa) se legitima gracias a la hegemonía preponderante que en esos discursos ejercen las pasiones sobre los actores sociales, lo que, lejos de aumentar el rendimiento narrativo, aplana al conjunto y exime a la misma pasión del más somero análisis. Por otra parte, como esos ensayos de emancipación moral eligen la ficción folletinesca como vehículo específico, no es raro constatar que sus relatos se elaboren también de forma doméstica, recombinando elementos extraídos de modelos más logrados, por ejemplo, las memorias y los relatos de viaje (señalemos, por ejemplo, las mismas "Recordações de viagem” de Manso, "O General Thomas Polegada e Ritinha a cubana” o "Casa de refúgio para os meninos e meninas pobres no estado de Pensylvania", divulgadas en el Jornal das Senhoras), relatos en su mayor parte masculinos, letrados y europeos. Se inscriben, por lo tanto, en una lógica de mestizaje cultural que construye identidades nacionales a partir de la idea de que la soberanía cultural no reside en rechazar lo otro sino en incorporarlo. Es en esa posición que debe ser evaluada Juana Manso: editora, traductora, narradora, en una palabra, mediadora, lo cual no disminuye sino que aumenta su interés. A ella se aplica la observación de un viajero francés de 1851, Emile Adet, la de que "une societé que se forme à la vie politique, qui travaille courageusement à concilier ses anciennes moeurs avec des institutions nouvelles, c'est toujours un curieux spectacle"11.

El diario de Manso salía los domingos. El primero de cada mes traía un figurín parisién y los otros tres, "um engraçado lundu ou terna modinha brasileira, romances franceses em música, moldes e riscos de bordados". Esas modinhas ou shotis eran, en su mayoría, del maestro Francisco Sá Noronha, esposo de la editora, lo que no excluía otros

11 Adet, Emile. “L”empire du Brésil et la societé brésilienne en 1850”. Revue des Deux Mondes. Paris, a. 29, n. 9 , 1851, p. 1083. 
sucesos de la época, como "Il Sospiro", una canzonetta con versos de Silvio Pellico, el autor de Mis prisiones y Francesca da Rimini, musicalizada por Lacourt. El Jornal das Senhoras era vendido en la Rua do Ouvidor, tanto en el $n^{0}$ 70, en lo de Wallerstein, como en el 86, la casa de F. Desmarais o al lado, en el 87, en lo de Mongie. En su primer número, Juana Manso exhorta a sus lectoras con el argumento de que

\begin{abstract}
A sociedade do Rio de Janeiro principalmente, Corte e Capital do império, metrópole do sul da América acolherá de certo com satisfação e sympathia o Jornal das Senhoras, redigido por uma senhora mesma: por uma americana que se não possue talentos, pelo menos tem a vontade e o desejo de propagar a ilustração e cooperar com todas as suas forças para o melhoramento social e para a emancipação moral da mulher. Eis-nos pois em campanha, o estandarte de ilustrações ondula gracioso à brisa perfumada dos trópicos; acolhei-vos a ele, todas as que possuis uma faísca de inteligência: vinde!
\end{abstract}

Esta americana que se adelanta a publicar un Jornal das Senhoras en su destierro, aunque poco conocida, no es sin embargo advenediza y apela al discurso autobiográfico como instancia prefacial de su diario femenino, menos para disminuir equívocos que para ilustrar la complejidad de la enunciación menor y su deseada emancipación. Sylvia Molloy ha mostrado, en At face value, el estatuto esquivo y elusivo de la memoria en los escritores hispanoamericanos del siglo XIX. La memoria es para ellos algo obvio, que se da por sentado, o bien un tono relegado a posición ancilar, doméstica, alternativas ambas que, hasta cierto punto, excluyen a la memoria del ejercicio autoconsciente de una escritura ${ }^{12}$. Pues Juana Manso o Joana Paula Manso de Noronha, sin exceptuarse a la regla, monta un juego de disfraces en su texto de presentación en el diario.

\title{
Quem eu sou e os meus propósitos
}

Fallar de mim mesma é uma triste tarefa.

Socegai porem minhas pacientes leitoras; não cuideis que eu vou agora fazer a minha biographia, ou contar-vos, (cá em confiança) de modo que todo o mundo possa ouvir, se fiz milagres desde pequenina, se improvisei romances aos oito annos de idade, etc., etc.

Nem julgueis que vou fazer-vos alguma relação romantica e poetica dos meus sentimentos, impressões e sensações... Deos nosso Senhor de tal me defenda.

12 Molloy, Sylvia. At face value. Autobiographical writing in Spanish America. Cambridge University Press, 1991. 
Confesso-vos entretanto que houve um tempo em que fui romantica da quinta essencia; mas no dia de hoje tudo mudou: é assim que é este mundo! eu á força de chorar acabei rindo-me, e fiz bem... Ao contacto dos vicios humanos, ao fogo activissimo dos desenganos do mundo, o meu coração encolheo-se e ficou secco, que nem pergaminho.

Mas em fim, quem sou eu?

Uma mulher escriptora; de mais á mais redigindo um Jornal; muita gente perguntará - quem é ella? -

Femme Auteur - Como dizem os Francezes.

Quem é ella?

Será velha ou moça?

Bonita ou feia?

Elegante ou excêntrica?

Sabeis o que estou eu ouvindo minhas queridas leitoras?

Pois ouço uma Corneta de caça que um Inglez toca horas inteiras dentro da sua sala; ah! só um Inglez podia ter a lembrança de tocar semelhante instrumento! Se pega a moda estamos bem aviadas.

Onde ficamos?

Ah! sim; dezejaes saber, ou vos perguntaes umas ás outras, se conhecem a Redactora do JORNAL DAS SENHORAS?

Não serei eu quem vos tire da curiosidade. Os poetas e a pintura devem sempre ver-se de longe; porém os poetas principalmente devem olhar-se a travez do prisma caprichoso da ilusão. Assim se goza dobradamente, e as vezes estima-se na fantasia um ser imaginario. Lembro-me sempre, que eu era apaixonada até o frenesi, das poesias de um Estevan Echeverria, aquem Alexandre Dumas, chamou - Lamartine Americano - esse moço, cujas rimas doce e sonoras penetravão como uma musica melodiosa até o fundo do meu coração, imaginava-o eu, pallido e formoso, meio homem meio arcanjo; e sobre tudo o que eu estava mais certa de encontrar nelle erão olhos grandes azues, de olhar profundo e sereno.

Ai! desgraçada!

Um dia aprezentarão-me Echeverria!

Era moreno, bexigozo, feio, e tinha olhos pequenos e vesgos!

Eu dei um grito involuntario, e esclamei:

Pois este!... é Echeverria!!!

Este! - segundo a entonação da minha voz, era o mesmo que dizer - este monstro! Foi uma dor mortal a que eu senti vendo o meu ideal despedaçado. Em quanto o pobre moço se deteve na minha casa, guardei-me muito bem de olhar segunda vez para elle, e depois, quando se foi embora, que eu evocava na solidade do meu pensamento a imagem do poeta dos meus sonhos, sempre se interpunha o espectro vesgo do tenebroso bexigozo.

Nunca mais li as rimas de Echeverria.

Por isso não vos direi quem eu sou.

Deixo-vos advinhar (não sou vesga nem bexigosa) e vou tratar dos meus propozitos.

Já sabeis que me proponho a escrever.

Fallar em differentes coisas, e sobre tudo, das mulheres, dos seus direitos, sua missão, etc.

Isto é, eu fallarei se Deos não dispuzer outra coisa, e se a este Jornal, lhe não acontecer o que aconteceo la na Espanha a um Tractado de economia politica de Bentham. Pois é o caso; que no anno de Graça de 182... quando El-Rei D. Fernando queria fazer reviver a Inquisição, houve prohibição formal sobre a introducção de livros, e quanto livro ía a Alfandega era levado a uma commissão de Domenicanos; quiz a desgraça que deparassem com o tal Tractado de economia politica, e immediatamente foi elle condemnado a auto de fé, como correligionario de Rousseau, Mirabeau e Voltaire!

Quem sabe, se o innocente JORNAL DAS SENHORAS, não vae soffrer algum auto de fé privado.

Fallar nos direitos, na missão da mulher, na sua emancipação moral!

Máo, máo; isto não é leitura que se deva permitir nas casas de familia. 
Mas Senhores, esperem um pouco; não lhes aconteça a historia do môno com a noz verde. - Já sabeis o mono trepou a nogueira, colheo uma noz, mordeo-lhe a casca, achou-a amargosa, e soltou a noz. Se elle tivesse tido a paxorra de ir mais adiante, não ficaria sem a comer.

Ora pois, isto que eu digo, é na supposição que haverá quem leia o que eu escrevo a esse respeito, do que eu tenho minhas duvidas, porque as vezes tambem acontece pregar-se o sermão no deserto; e eu, desde que ha dias deparei com uma folha do Judeu Errante Embrulhando assucar - para logo fiz tenção de pedir ás minhas assignantes de fazerem encadernar este Jornal, bem encadernadinho.

Em fim, vamos adiante; sem duvida é assas monstruoso neste seculo das luzes, (em que todo o mundo está às escuras) não prestar ouvidos attentos ao Jornalista que vae tratar sobre assumpto tão interessante, como é o destino da porção a mais bella da humanidade; porém o que seria mais monstruoso e inaudito era que - os outros ouvissem sem ninguem lhes fallar attendendo pois a esta consideração, que é de grande pezo, irei adiante com a minha tarefa; e em nome de Deus - en avant.

Buena parte de la ambigüedad de Manso proviene del doble destinatario de su discurso. Por un lado, la sociedad imperial, donde ejerce papel de árbitro estético, pero por el otro, la sociedad argentina sobre la cual no abdica de influir. En el número del 21 de marzo de 1852, Manso dirige una carta abierta a Alsina, protagonista de su folletín Misterios del Plata, confesándole que "mui satisfeita ficaria eu se a aprovação coroasse os meus esforços; e, se V. m. o permite, continuarei enviando-lhe pelo paquete o seguimento do romance, o qual muito prazer teria que se publicasse em espanhol, para cujo fim já escrevi ao meu primo Reissig, para abrir assinaturas em Montevidéu e Buenos Ayres".

Como índice de ese doble registro, mediador entre lo interno y lo externo (hablándole a la nación y a la subjetividad), uno de los primeros folletines divulgados por el diario de Manso, que circulará en Rio hasta fines de 1855, es algo, efectivamente, otro: una "novela polonesa", Karolina, traducida del francés por la redactora en jefe; pero la que nos ocupa en particular es la que su autora califica de "romance histórico contemporáneo", Misterios del Plata. Sabemos que, en la primera versión de la novela, publicada póstumamente en 1899, Juana Manso en sintonía con las vidas infames relatadas por la literatura y la ciencia de fines de siglo, justifica el título de su novela por el enigma histórico de las biografías bárbaras. El eje entonces es Rosas:

Al poner a esta obra el título de "Misterios del Plata"; no es mi ánimo imitar los Misterios de Paris de Eugenio Sué, ni hacer otros Misterios de Londres.

Mi país, sus costumbres, sus acontecimientos políticos y todos los dramas espantosos de que sirve de teatro há ya tantos años, son un misterio para el mundo civilizado.

Misterios negros como el abismo casi increibles en esta época y que es necesario que aparezcan á la luz de la verdad para que el crimen no pueda llevar por más tiempo la máscara de la virtud; 
para que los verdugos y las víctimas sean conocidas y el hombre tigre - conocido hoy con el nombre de Juan Manuel Rosas, ocupe su verdadero puesto en la historia contemporánea; el de un tirano atroz y sanguinario tan hipócrita como infame. ${ }^{13}$

Pero, en cambio, la versión de 1852 no está muy lejos de las teorizaciones de Echeverría en su Ojeada retrospectiva sobre el movimiento intelectual en el Plata desde el año 1837, en el sentido que "el arte americano, democrático, sin desconocer la forma, puliéndola con esmero, debe buscar en las profundidades de la virgen, grandiosa naturaleza americana" su fundamentación histórica, sus materiales constructivos. Cotejemos:

Não foi por servil imitação aos "Mystérios de Paris", e aos de Londres, que chamei a este romance "Mysterios del Plata". Chamei-o assim porque considero que as atrocidades de Rosas e os soffrimentos de suas vítimas serão um mystério para as gerações vindouras, apezar de tudo quanto contra ele se tem escripto. Mais poderosos que seus inimigos, seus escritores assalariados contrabalançam o brado dos contrários do tirano; e, outras vezes, esses mesmos escriptos comprados pelos seus agentes são aniquilados.

Este mesmo risco corremos nós, porém, que fazer? é necessário resolvermo-nos a tudo, além do que, se a nascente literatura da nossa América for sempre buscar seus typos na velha Europa, nunca teremos literatura americana, nem literatura nacional.

Levantar o veo funerario do nosso passado; custa-nos muito; porque, d"entre esse mar escarlate do mais puro sangue argentino, vemos levantar-se pallidos e medonhos os spectros de nossos amigos, de nossos irmãos... Com tudo, como a ultima flor depositada pelo peregrino na porta do lar domestico que vae abandonar, nós escrevemos este romance nas agonias do amor patrio que se extinguia; e quando a força de soffrer, fomos arrastados ao cosmopolitismo indifferente.

Hoje cuidamos de não bolir na ulcerada chaga que nos deixarão nossas dissipadas illusões, as nossas derrubadas esperanças; é uma dor que ficou no fundo do coração, derradeira saudade tão duradoura como a existencia.

Neste romance encontrareis talvez o que ainda se chamão ideas "muito livres" porque, apezar de sua civilisação, o seculo 19 conserva preconceitos e horrores, e mesmo frente a frente com a verdade, custa-lhe sabir do gothico edificio, cujos carcomidos alicerces por toda a parte se desmoronão.

$\mathrm{Eu}$, infelizmente talvez, nunca serei servil, nem nas minhas opiniões, nem nos meus escriptos; considero que a percepção das verdades eternas, é um tesouro depositado por Deos no espírito humano, não para ser occulto; ou esquecido, mas sim para revela-lo aos homens com voz sonora e porte altivo.

O apostolado da siencia da verdade é digno de todo aquelle que sente força no coração e no espirito para o sustentar.

Não sei quantos defeitos, nas formas, encerrará este romance; nunca cuidei das regras, porque entendo que a regra verdadeira de toda a composição, é a inspiração; nada tão robusto e perfeito como o pensamento, dom de Deos, e que criando, a Elle nos assemelha, porque como Elle, tambem cria.

Depois de tudo, ca escrevo, porque a isso tenho sido arrastada, eu não sei como...

13 Noronha, Juana P. Manso de. Los misterios del Plata. Novela histórica original. Buenos Aires. Imprenta los Mellizos, 1899, p. 3. 
Tenho luctado, e porfim venceo alguma cousa que existia desconhecida no intimo de mim mesma, e a cujo impulso obedeço.

Assim, pois, eis o meu romance verdadeiro: suas personagens, algumas ainda existem.

A historia d"essa heroica Argentina é mais um facto que prova a necessidade da illustração das mulheres; não só em proveito de si mesmas, quanto em proveito do homem, de que são ellas a companheira e o segundo chefe da familia. ${ }^{14}$

Es ese espíritu genealógico americanista, un poco a la Gutiérrez, el que anima, en El inválido argentino, a fines de 1867, su versión anterior, de 1846-7, previa por tanto a la del Jornal das Senhoras, titulada "Guerras civiles del Rio de la Plata. Primera parte: Una mujer heroica”, versión ésta firmada por Violeta. Precede ese antetexto justamente de una ojeada retrospectiva que le ofrece el marco en cuyo interior se inscriben los personajes, según ella próximos a la historia, que actúan en su ficción. La autora de La Revolución de Mayo argumenta en ese entonces que

El romance historico de nuestras guerras civiles, tiene personajes reales que han sufrido y actuado en ellas; los colores locales y los accesorios del cuadro, son del dominio de la fantasia del pintor que unas veces copia de la naturaleza y otras crea, inspirándose en el corazon.

Estos croquis, tal vez imperfectos, fueron trazados por mi en edad muy temprana, y vieron la luz de la publicidad en pais lejano é idioma estraño, cuando Rosas ocupaba todavia en Buenos Aires la silla dictatorial, y yo no tenia esperanzas de volver a la patria.

Si algun mérito tienen, es la pretension de conservar a los venideros, la tradicion escrita de los dolores que han trabajado nuestra sociedad, y de las virtudes ignoradas cuya memoria debe perpetuarse en la memoria de las jentes por un deber de justicia.

No es mi ánimo reanimar la llama de estintos rencores, ni alimentar la prexistencia de ódios acerbos de partido; pero la historia íntima de los hechos familiares debe no solo salvarse del olvido, sino utilizarse como leccion provechosa de lo que importa el despojo de las libertades públicas y de los derechos individuales.

Las guerras civiles del Rio de la Plata, constarán de dos partes; la primera, sin nombres propios, será el romance de una mujer que ya no existe pero que aun tiene próximos deudos, y que será facilmente conocida; la segunda parte se denominará: Pajinas de la Juventud y contendrá mas de un nombre propio, como crónica social de los incidentes de una época política, separada de nosotros por el lapso de 28 años.

Pido anticipadamente a alguna de mis lectoras, que no se escandalice si ve su nombre en letra de molde: la historia y el romance son de la propiedad del artista. ${ }^{15}$

Pero aunque la convención ficcional de Guerras civiles del Rio de las Plata feche la redacción contemporáneamente a los hechos narrados, el postfacio de Misterios del Plata redactado el 2 de junio de 1852 (coincidiendo con la salida de Manso de la redacción del

\footnotetext{
${ }^{14}$ Idem. "Misterios del Plata". Jornal das Senhoras. Rio de Janeiro, 11 enero 1852, p.14.

15 Violeta. "Una mujer heroica" (primera parte de "Guerras Civiles del Rio de la Plata") in El inválido argentino, Buenos Aires, a. 1.,n. 53, 29 dic 1867, p. 417.
} 
Jornal das Senhoras), reconstruye las circunstancias en que cristaliza la idea de su novela histórica. Aclara entonces su autora:

\begin{abstract}
Comecei a esboçar este romance em Philadelphia, en 1846, foi concluído na fortaleza do Garavatá, onde morei 5 meses, en fins de 1849 e principios de 1850.

Temia-o publica-lo porque a mor parte das personagens vivas ainda, sobretudo Rosas, não me perdoaria facilmente a revelação de factos que muitos não acreditão, e são pela nossa desgraça assás veridicos.

Os Mysterios del Plata não são mais do que o começo de uma serie de romances históricos que apparecerão mais tarde; se me for possível dar-lhes publicidade. O epílogo do presente romance não é possível por ora publicar-se no Jornal das Senhoras por inconvenientes independentes de nossa vontade, mas estamos disposta, sempre que acharmos cooperação, a fazer uma edição dos Mystérios acompanhada então do epilogo.

Como sabeis, leitoras, depois da queda do tyrano, Alsina foi chamado ao ministerio. Assim devia de ser, hoje pediu a sua demissão e se retirou à vida privada; é a última prova que esperávamos do nosso herói, a quem mais ainda uma vez prestamos nossa homenagem de admiração e respeito.
\end{abstract}

Pero si clasificamos la novela de Manso de folletín genealógico, sería conveniente anotar que, además de estos Misterios del Plata, el Jornal das Senhoras reedita otros ejemplos del género como la conocida "novela brasileira", Amor, ciume e vingança del precursor J. M. Pereira de Silva (1817-1898). Político y polígrafo, autor del Parnaso Brasileiro, el Plutarco Brasileiro y Varões ilustres do Brasil, a partir de 1839 Pereira da Silva publica las primeras novelas históricas del país: Religião, amor e pátria y O Aniversário de D. Miguel em 1828, Jerônimo Corte Real (1840), Manuel de Morais, Aspásia, "novela portuguesa contemporánea” y D. João de Noronha, ya en los años 80. Poco después de esta última, la Biblioteca da Livraria do Povo, incluye su $A$ História e a Legenda, según la propaganda, "interessante e utilíssima obra do abalisado historiador brasileiro conselheiro João Manuel Pereira da Silva, três grossos volumes de mais de 1.000 páginas $9 \$ 000 ”$. Pues en una de ellas, encontramos un retrato de Rosas construído ciertamente a partir de los materiales aportados, entre otros, por la redactora del Jornal das Senhoras:

Proclamada a independencia, e abraçado o systema republicano no antigo vice-reinado hespanhol do Rio da Prata, não habituados ainda os povos á liberdade, e nem educados com governo proprio e garantidor de direitos sociaes, individuaes e politicos, começou a anarchia, em consequencia de ambições desordenadas, e de guerras civis, resultado infalivel dos succesos occoridos.

Anciava, portanto, o povo paz, tranquilidade e ordem, e como a historia ensina, da anarchia recorreu-se para a dictadura, medida considerada de salvação publica. 
Segue-se sempre á anarchia o regimen dictatorial. Não está ahi a historia para apontar Julio Cesar em Roma, Cromwell em Inglaterra, e Napoleão Bonaparte em França?

Rosas symbolisava o governo dictatorial; e como gaúcho, caudilho, commandante de forças mais ou menos arregimentadas, representava o militarismo. A nação queria paz que lhe importava a escravidão?

Que se notava na hediondez da abjecção? Delatores e espiões por toda a parte; denuncias repetidas e provocadas, e certas de exito afortunado. Quem não tinha inimigos, invejosos, desafectos? Prescrutava-se o pensamento, invertiam-se as palavras, adulteravam-se os gestos. Era até perigoso merecer a protecção do dictador e alcançar lhe as graças. Não se mostram sempre em identicas circumstancias mais zelosos da reputação do amo seus satelites e escravos? Não foi Nero felicitado pelo assassinato da mãe Agripina?

Habituou-se, pois, o povo, á servidão, perdeu toda a energia, e desprendeu-se de todos os brios humanos.

Cessaram lamentações, seccáram as lagrimas pelos soffrimentos alheios ou proprios; em saudações espraiava-se o terror; em gratidão á Deus convertia se a era feliz em que governava um chefe, que mantinha a ordem publica, castigava os discolos, e salvava a nação de revoltas. Tal era a situação, a que Rosas reduzira Buenos Ayres. ${ }^{16}$

Aunque no hayan compartido, como en el caso de Pereira da Silva, temas comunes con Juana Manso, deberíamos aquí consignar otros tantos precursores de la novela histórica brasileña, activos en la capital del Imperio durante el exilio de Manso. Justiniano José da Rocha (1812-1862), colaborador en la Revista da Sociedade Filomática (1833) de São Paulo, concluye Os assassinos misteriosos ou a paixão dos diamantes en 1839, siendo también autor de O Paria e a Sociedade Brasileira y de muchísimas traducciones de Charles Bernard, Eugène Scribe o Tanny Lewald, incluyendo dos obras capitales del período, El Conde de Montecristo (1845) de Alejandro Dumas y Los miserables (1862) de Victor Hugo. Martins Pena, más conocido como dramaturgo, llega a publicar en 1840, en el Sentinela da Monarquia o en el Correio de Rio de Janeiro, la novela histórica Duguay-Trouin. Joaquim Norberto de Souza e Silva (1820-1891) también como Pereira da Silva, doublé de narrador, crítico y político, fue colaborador activo en las revistas literarias del momento, entre ellas, la Minerva Brasiliense (1843-1845), donde incluye unas indagacõoes sobre literatura argentina, muy en sintonía con las ideas de Gutiérrez y Echeverría; la Guanabara (1850-55); la Revista do Instituto Histórico o la Revista Popular. En términos narrativos publica en 1841 As duas órfãs; en el 43, Maria ou vinte anos depois y el mismo año que los Misterios, otros dos relatos: Januario Garcia y O Testemunho Falso hasta que, en 1884, divulga en la Gazeta Universal su novela Chegado de Londres e vindo de París. Gonçalves de Magalhães (1811-1882), unánimemente

\footnotetext{
16 Pereira da Silva, J. M. A história e a legenda. Rio de Janeiro, Livraria do Povo, 1896, p. 314-5.
} 
http://dx.doi.org/10.5007/1984-784X.2012v12n18p61

considerado el introductor del romanticismo en Brasil y cuyo retrato debemos a Gutiérrez, es autor de un cuento pionero, Amancia, pero también de un interesantísimo texto, $A$ revolução da provincia do Maranbão desde 1839 até 1840, "memória histórica e documentada", publicada en São Luiz en 1858 y que puede ser leído como un antecedente de Os Sertões de Euclides da Cunha. De 1845 son las novelas históricas de Vicente Pereira Carvalho Guimarães (1820-?) quien, a través del periódico que editaba, el Ostensor Brasileiro, va a narrar las peripecias de un caudillo popular en una rebelión del siglo XVII, Jeronimo Barbalho Bezerra, además de $A$ cruz de pedra, A guerra dos emboabas y un folletín inconcluso sobre $O s$ jesuitas na América, lo cual nos habla de una disposición, entre balzaquiana y anti-liberal, ante la cuestión de culto y política ${ }^{17}$.

Teixeira e Souza (1812-1861) es autor de Gonzaga ou a Conjuração de Tiradentes (184851) y As fatalidades de dois jovens. Recordações dos tempos coloniais (1856). Joaquim Manuel de Macedo (1820-1882), ya referido, publica, en 1844, A moreninha, novela sentimental canónica, a la que siguen, en folletines del Correio Mercantil, entre 1852 y 53, las Memórias de um sargento de milícias, uno de esos libros al margen de las literaturas, como lo clasificó Mário de Andrade quien, no sin señalar su filiación picaresca ibérica, encomia la rebelión ética, no siempre progresista, que situa a su autor contra la retórica dominante "e antes de mais nada contra a vida tal como ela é, que eles então gozam a valer, lhe exagerando propositalmente o perfil dos casos e dos homens pelo cômico, pelo humorismo, pelo sarcasmo, pelo grotesco e o caricato" ${ }^{\prime 18}$. Nada de esto, evidentemente, se observa en Manso, aun cuando todo esto sea visible en Los misterios del Plata cuyo lenguaje, según su autora aunque fiel a los usos del país, "si alguna diferencia tiene es una ventaja, es decir, menos grotesco", o sea, producido por un narrador que se identifica con el sujeto universal de la razón o de la ley.

En estas ficciones genealógicas se da entonces una doble paradoja, lo grotesco de lo grotesco. Se insertan episodios nacionales en el marco de principios historiográficos ideales de la filosofía o del derecho pero, al mismo tiempo, al agruparse en el movimiento sostenido e indefinido de la historia, esos hechos acaban recortándose como fábulas

\footnotetext{
${ }^{17}$ Me ocupé de él y sus relaciones con los emigrados argentinos en Algaravia. Teoria da nação. Florianópolis, Editora da Universidade Federal de Santa Catarina, 1998.

18 Andrade, Mário de. "Introdução" a Memórias de um sargento de milicias. São Paulo, Martins, 1941.
} 
identitarias dotadas del vigor de un mito fundacional. La verdad, tan declarada y ostensivamente perseguida por sus autores, funciona entonces como un discurso oscuramente crítico y, al mismo tiempo, intensamente mítico. De allí sus victorias proclamadas y sus límites eufemizados.

Es verdad que Pereira da Silva escribe novelas históricas a la zaga del portugués Alexandre Herculano, así como Alencar sumaría a ésa la influencia de Walter Scott. Es verdad que Carvalho Guimarães o Teixeira e Souza eligen a los jesuitas y las luchas de ocupación como tema de sus relatos, materiales de que Alencar se va a valer en un drama, O Jesuita, para señalar el peligro inminente de una nación en el interior de otra, cosa por lo demás ya señalada, en clave épica, por Basílio da Gama en O Uruguai. Es verdad que de la rebelión inconfidente de 1789 el poeta Tomás Antonio Gonzaga emerge como figura fácilmente novelable, atendiendo al ideologema poeta $=$ profeta, central en la poética heroica de los románticos. Pero no es menos cierto que ya sea por desconocimiento del pasado colonial (gracias a la proverbial ausencia de Universidades en la Terra de Santa Cruz, paliada, parcialmente, con la llegada al Brasil de D. João VI y, más tarde, con la fundación del Instituto Histórico y Geográfico) o por falta de familiaridad con los mismos modelos extranjeros, no fue la novela histórica un género dominante en la incipiente narrativa brasileña de comienzos del XIX. No es ajeno a ello el fuerte individualismo, no exento de violencia, que comanda todo el proceso de consolidación del Estado. Un subjetivismo que no desdeña sino que aprecia y abusa de la confesión y la tendencia lírica, persiguiendo un ideal político de vida social armoniosa, con el irresistible triunfo de la benevolencia y mutua comprensión entre los ciudadanos, virtudes pautadas más por obra del destino que de una deliberación ética o nacional de los protagonistas, lo que merece y justifica, por ejemplo, el recurso epistolar, algo que si bien nos distancia de la óptica muralista de la novela histórica, por otro lado, acentúa los procedimientos constructivos autoconscientes que sostienen la ficción moderna. Ese es el campo en el que emerge en Brasil la ficción genealógica.

Pero los Misterios del Plata no dialogan solamente con el relato histórico brasileño. Son asimismo impensables sin el concurso combinado de la novela sentimental o del relato de viajes europeo. Tomemos, a título de ejemplo, el primer capítulo del folletín. No había, a 
excepción de las crónicas extranjeras, registro de la estancia cuando Juana Manso describe

la azotea y fija en ella la vida de la peonada y las mujeres oyendo las décimas amorosas del payador, suerte de Ur-fantasia gauchesca ${ }^{19}$.

Podemos más por sus diferencias que por sus semejanzas equiparar esa azotea al cuadro que otra mujer, Lina Beck, nos presenta en 1864:

L'estancia de Santa-Rosa, qui avait pour seigneur et maître don Estevan Gonzalès, passait, et avec raison, pour l'une des plus belles du campo. Construite au temps des vice-rois, elle se distinguait par sa solidité et ses vastes proportions. Le principal corps de logis était de ce style oriental que les Andalous ont emprunté aux Maures, et qu'ils ont transporté, sans aucune altération, dans la province de Santa-Fé. Les chambres de la maison étaient disposées autour d'une cour carrée ou patio dont le centre était occupé par une citerne surmontée d'un puits qu'ornait une arcade mauresque en fer ouvragé. Une magnifique veranda garnie de vigne donnait une ombre fraîche et délicieuse au large trottoir sur lequel s'ouvraient les portes des appartemens principaux. Dans chaque angle du patio se dressait une énorme amphore en terre rouge, appelée tinacone, et destinée à rafraîchir l'eau pendant les chaleurs de l'été. Après cette première cour, il en venait une seconde, puis une troisième. Des groupes d'orangers et de palmiers, entremêlés de citronniers et de lauriers-roses, en occupaient le milieu et les côtés. Au fond, dans un coin, se trouvaient les dépendances de la maison, cuisine, chambres de domestique, etc. L'estancia de Santa-Rosa étant isolée, on l'avait bâtie de manière à pouvoir résister à une attaque. Ses très rares fenêtres à l'extérieur étaient garnies de solides barreaux de fer. Les murs des cours, très élevés, épais, construits en pisé, avaient un revêtement de briques. Au-dessus de la porte d'entrée, une chambre unique, nommée altillo, ayant la forme d'un cube en maçonnerie, offrait un mirador ou balcon, d'où le regard s'étendait fort loin. Le toit plat de l'altillo formait terrasse. En temps de troubles, on y établissait un canon: ce n'était, à vrai dire, qu'un vieux tuyau de poele monté entre deux roues de charrette; mais cette inoffensive machine avait de loin un aspect formidable, et son profil menaçant, qui se détachait sur l'azur inaltérable du ciel, avait écarté plus d'une fois les maraudeurs peu curieux de la mitraille. Don Entevan se piquait, du reste, d'être un homme à précautions. Il étalait avec orgueil dans sa chambre quelques antiques carabines espagnoles, à crosses d'ébène incrustées d'argent, que ses ancêtres avaient apportées d'Andalousie; c'étaient, il est vrai, de lourds et incommodes engins, tout au plus propres à la parade. Les péons, qui les contemplaient avec la répugnance instinctive des gens du pays pour les armes à feu, ne se fiaient, eux, qu’à leurs couteaux et à leurs lassos, et, la fronde à la main, ils se sentaient suffisamment protégés contre toute attaque indigène.

Au côté nord de la seconde cour s'élevait une petite chapelle dédiée à sainte Rose, dans laquelle un padre, missionnaire franciscain, venait un jour chaque mois dire la messe. C'était un ancien édifice en briques que le temps avait bruni. Un portail, entre deux pilastres, était surmonté d'une architrave au-dessus de laquelle une sorte d'enfoncement dans le mur abritait la statue de sainte Rose de Lima, patronne de l'Amérique du Sud. Cette statue, faite au Pérou, était de bois, peinte à l'huile et chargée d'ornemens dorés. Sa couronne de roses, fleurs qui ne manquent jamais dans ces beaux climats, était renouvelée chaque jour par les soins des femmes de l'estancia. Au-dessus de la statue s'élevait une petite tourelle surmontée d'une coupole où pendait une cloche, à laquelle la pluie et le soleil avaient donné une belle teinte de vert-de-gris. A l'extérieur, l'estancia était entourée de plusieurs corrals, enceintes circulaires faites de pieux très serrés, et où l'on enferme le soir le bétail auquel on tient particulièrement, comme les chevaux

${ }^{19}$ Noronha, Joana P. Manso de. "La estancia", "Guerras civiles en el Rio de la Plata" in El inválido argentino, op. cit., p. 417-8 y Los misterios del Plata. ed. de 1899, p. 5-9. 
de prix, les bœufs d'attelage, les chèvres et les moutons, un autre les mulets, désagréables compagnons qu'il faut laisser seuls. Auprès, et à l'ombre de quelques arbres gigantesques nommés ombùs, ou voyait plusieurs petits ranchos de briques sèches et de paille, où logeait le personnel très nombreux de l'estancia. Une maisonnette plus grande et plus jolie que les autres servait de demeure à Demetrio, le majordomo ou chef de l'escouade des capatas, chargés des soins du bétail: ceux-ci ont à leur tour sous leurs ordres les péons, qui sont, à proprement parler, les bergers, armés et à cheval, gardant les troupeaux, souvent à plusieurs lieues de distance, et menant l'existence nomade des peuples pasteurs de la Bible. ${ }^{20}$

No hay, como se puede fácilmente observar en el relato de la viajera, ninguna referencia al gaucho. La estancia es una unidad productiva inscripta en el sistema patriarcal e interesa mucho más verla como construcción de un habitat, rigurosamente revelado de acuerdo a la ambición nomencladora del efecto de real, que como un paisaje apropiado a partir de una inversión afectiva, ya sea desde la óptica normalista de Manso, ya desde la transgresiva y nómade del gaucho. Es ésta la que tan sólo seis años más tarde, e igualmente en París, va a surgir como cuadro definitivo de la estancia. El Santos Vega de Ascasabi, en efecto, nos presenta la estancia de la Flor a partir de su sólida fuerza ctónica, un ombú centenario,

el más soberbio/que en esos campos se vió,/erguido se interponía/entre la tierra y el sol,/cubriendo de fresca sombra/a un inmenso caserón/de ochenta varas en cuadro,/trabajado con primor,/de adobe crudo, tejado,/y madera superior.

Todo el frente que habitaba/la familia del patrón,/del lado que hacía al campo/y de la banda exterior,/con arcos de largo a largo/lo ceñía un corredor,/y también a un oratorio,/de lo lindo lo mejor./Después, en los otros puntos/tenían colocación:/una tahona, dos cocinas,/el granero y el galpón/del uso de la pionada;/y en seguida otro mayor/para apilar el cuerambre,/y en cierta separación/el sebo, la cerda y lana,/con toda ventilación./De ahi, palomar y cochera,/y después la habitación/que ocupaba el mayordomo;/y al lado un cuarto menor/que guardaba un armamento/nuevito y de lo mejor./Luego, otras piezas asiadas/donde metía el patrón/a las gentes de su agrado,/cuando era de precisión.

Además de eso, a la casa,/por si acaso, a precaución,/la rodeaba toda un foso/de cinco varas de anchor,/y profundo, de manera/que agua nunca le faltó.

Ansí, del lado de adentro,/de la zanja alrededor,/sauces coposos y eternos/ostentaban su verdor;/y álamos que hasta las nubes/se elevaban por su altor,/hacían de aquella estancia/un palacio encantador.

Después de eso, una estacada/de ñandubay de mi flor,/tan pareja y tan fornida/que el poste más delgadón/no lo arrastraba una cuadra/el pingo más cinchador,/a todito el caserío/le servía de cordón,/dejando entre la estacada/y la paré un callejón/para andar holgadamente,/y pelear en la ocasión;/pues para eso en cada esquina/arriba de un albardón/como triángulo empedrao,/estaba listo un cañón;/y en la de junto al potrero/en vez de uno había dos,/defendiéndole la entrada./Ansí no había temor,/encerrando allí la hacienda/en caso de

20 Beck, Lima. "L"estancia Santa Rosa. Scènes et souvenirs du désert argentin". La Révue de Deux Mondes. Paris, vol. 54, 15 nov 1864, p. 322-3. Medio siglo más tarde, otro viajero, Le Corbusier, elogiará la azotea como la gran contribución criolla a la arquitectura moderna. 
una invasión/de los pampas o ranqueles,/que entonces daban terror,/pues en cada luna llena/caiban como nubarrón/a robar en las estancias,/y matar sin compasión,/quemando las poblaciones/entre algazara y furor./Pero no facilitaban/en la estancia de la Flor,/donde, si se aparecían,/en levantando un portón/que hacía de puente al foso,/con toda satifaición/se les peleaba de adentro/como del fuerte mejor.

Afuera estaba la chacra,/en tan linda situación,/que un arroyo la cercaba/para regarla mejor. Luego, había tres corrales/de suficiente grandor:/dos para hacienda vacuna,/en los que sin opresión/cabía todo un rodeo/mansito y resuperior./Después, el tercer corral/tan sólo se destinó/para encerrar las manadas,/que eran una bendición,/mucho más la de retajo,/del esmero del patrón,/por la multitú de mulas/que esa manada le dió;/de modo que, año por año,/remitía una porción/para los pueblos de arriba:/trajín que lo enriqueció./Luego, para la majada,/al ladito de un galpón/que cubría seis carretas,/un bote y un carretón,/dejando el chiquero aparte,/el corral se les formó;/y para cuidarla bien/ahi mesmo a la inmediación/dormían los ovejeros,/cada perro como un lión/que toriaban al sentir/el más pequeño rumor.

Tal era la estancia grande/que don Faustino pobló,/conocida allá en su tiempo/por la estancia de la Flor $(. . .)^{21}$

En el proceso genético de Los misterios del Plata, Juana Manso mostró que la historia sólo puede ser apropiada si previamente ha sido constituida como objeto. Como la narración de Michelet, su novela histórica se desdobla en la pregunta por los límites del acto. Su historia se encuentra, así, consumada o sobreseída, es decir, en parte, cumplida, y por otro lado, canibalizada para, gracias a ella, resucitar al historiador que de esa historia extraerá un ejemplo de vida. En Fervor de Buenos Aires, visitando la Recoleta, Borges comprende "los muchos ayeres de la historia/hoy detenida y única". Mucho antes, sin embargo, Manso, en Los misterios del Plata, ensaya la misma disposición de espacio y tiempo como categorías del yo y lo hace a partir de un cierto hastío, sentada, "largas horas à borda dos túmulos” de esa misma Recoleta. Ilustra así el epígrafe, extraído de la Historia de Francia de Michelet, que ella misma copió a cada comienzo de entrega de Los misterios del Plata:

Com o mundo começou uma luta que só com o mundo mesmo acabará, não antes: a do homem contra a natureza, a do espírito contra a matéria, a da liberdade contra a fatalidade. A história não é outra coisa que a relação desta interminável luta.

Más que un misterio, esa narración histórico-folletinesca nos propone un enigma: el problemático deslinde entre lo letrado y lo masivo en una cultura de modernización emergente. No faltaron ensayos: los Mistérios da roşa ou Misérias da atualidade (1864) de

\footnotetext{
21 Ascasubi, Hilario. Santos Vega in Poesia Gauchesca. Ed. prólogo notas y glosario de J. L. Borges y A. B. Casares. Mexico, Fondo de Cultura Económica, 1955, p. 325-9.
} 
Vicente Felix de Castro, los Mistérios da Tijuca o Girândola dos amores (1882) de Aluísio Azevedo, esto sin contar los Mistérios da estrada de Sintra de Eça de Queiroz o los de Rio de Janeiro que se compondrían con los relatos folletinescos de Machado de Assis. Esos tableaux urbanos se concretarían, sin embargo, en 1925, con los Mistérios do Rio de Janeiro, de Benjamin Costallat, narrador y dandy muy apreciado por Blaise Cendrars, o en 1973 con Manuel Puig, cuyo The Buenos Aires affaire obtiene, en su versión francesa, la verdad de una reconstrucción retroversa, vengadora de Sue: Les mystères de Buenos-Ayres. Ante esos relatos podemos pensar que perseguir deliberadamente lo popular configura, con benevolencia, una bella ilusión niveladora, de homogeneización tan normativa como inconsecuente o, en perspectiva menos tolerante, una utilización pintoresquista y sofisticada que refuerza los estereotipos dominantes y su misma capacidad de perduración y hegemonía, perspectiva que, sin embargo, no está exenta de tensiones. El hecho de que Manso - una mujer, una educadora - se valga de esa forma artística europea y estatalista la incluye en la cruel admonición con que Mármol añora la estabilidad de su patriarcalismo, tan modernizador como autoritario:

Pobre America minha! Tu conservavas em teus velhos costumes o que devia ser para sempre velho; isto he, querias que tuas mulheres fossem mulheres: porém, quão longe estavas de pensar que, ao fazer com a Europa os teus tractados de amisade e commercio, a tua boa amiga te introduziria por contrabando, entre os caixões de suas mercadorias, o grande-tom de sua moderna sociedade. Esse grande-tom, que, a força de engrandecer-nos, faz rebentar a muitos de nós!

$\mathrm{E}$, o peor he que não ha remedio, para semelhante mal. ${ }^{22}$

22 Mármol, José. "Fragmentos de minha carteira de viagem”. Ostensor Brasileiro. Rio de Janeiro, 1845, p. 220. 